\title{
Associated factors in high blood pressure among schoolchildren in a middle size city, southern Brazil
}

\author{
Cristine B. Costanzi, ${ }^{1}$ Ricardo Halpern, ${ }^{2}$ Ricardo Rodrigo Rech, ${ }^{3}$ \\ Mauren Lúcia de Araújo Bergmann, ${ }^{3}$ Lidiane Requi Alli, ${ }^{3}$ Airton Pozo de Mattos ${ }^{4}$
}

\begin{abstract}
Objective: To establish the prevalence of high blood pressure and associated factors among schoolchildren from Caxias do Sul, state of Rio Grande do Sul, Brazil.

Methods: This school-based cross-sectional study assessed boys and girls aged 7 to 12 years from private and public schools. Three measurements of the children's blood pressure were taken during one visit to the schools. Weight, height, and waist circumference were measured. We also assessed the children's aerobic capacity (9-minute running test) and socioeconomic status. Statistical analysis was carried out using the chi-square test and logistic regression in order to control for confounding factors.

Results: The sample included 1,413 children. Prevalence of schoolchildren with high blood pressure was $13.8 \%$ (systolic, diastolic, systolic/diastolic), and the proportion was higher (double) for obese and/or overweight children in comparison to normal-weight children. Children with increased waist circumference had 2.8 times greater chance of having high blood pressure levels than those with appropriate waist circumference $(95 \%$ confidence interval 2.513-3.186 and $p=0.000$ ). Individuals belonging to a high social class, defined according to the Brazilian National Economic Index, had 2.6 times greater chance of having high blood pressure.

Conclusions: In the present study, schoolchildren aged 7 to 12 years from Caxias do Sul had high prevalence of high blood pressure levels; increased waist circumference, high socioeconomic status, and low physical capacity were associated with this condition. We suggest that measures be taken to promote the practice of physical activity and dietary control to improve blood pressure levels and thus reduce risk factors.
\end{abstract}

J Pediatr (Rio J). 2009;85(4):335-340: Children, blood pressure, epidemiology, obesity, physical capacity.

\section{Introduction}

Systemic hypertension is a condition that affects approximately $30 \%$ of the adult population, being the cardiovascular disease responsible for the greatest number of deaths in the world. ${ }^{1}$

In Brazil, systemic hypertension affects 14 to $18 \%$ of the adult population. Due to its high prevalence and because it is one of the greatest risk factors for cardiovascular diseases, it has a significant influence on the population's quality of life, being ranked first among the pathologies that determine the years of life lost due to early death.2,3

Many studies have demonstrated strong evidence that systemic hypertension in adults has its onset during childhood. ${ }^{4,5}$ Although essential hypertension in children is not a risk factor for cardiovascular events during childhood, cardiovascular and hemodynamic alterations have been detected in these individuals since their second

1. Fisioterapeuta. Mestre, Saúde Coletiva, Universidade Luterana do Brasil (ULBRA), Canoas, RS, Brazil.

2. Doutor, Pediatria. Professor, Curso de Mestrado em Saúde Coletiva, ULBRA, Canoas, RS, Brazil. Professor, Universidade Federal de Ciências da Saúde de Porto Alegre (UFCSPA), Porto Alegre, RS, Brazil.

3. Educador(a) físico(a). Mestre, Saúde Coletiva, ULBRA, Canoas, RS, Brazil.

4. Doutor, Educação. Professor adjunto, Curso de Mestrado em Saúde Coletiva, ULBRA, Canoas, RS, Brazil.

No conflicts of interest declared concerning the publication of this article.

Suggested citation: Costanzi CB, Halpern R, Rech RR, Bergmann ML, Alli LR, de Mattos AP. Associated factors in high blood pressure among schoolchildren in a middle size city, southern Brazil. J Pediatr (Rio J). 2009;85(4):335-340.

Manuscript submitted Apr 4, 2008, accepted for publication Apr 152009

doi:10.2223/JPED.1913 
decade of life or even earlier. ${ }^{6}$ Some factors have been consistently proven to be associated with higher blood pressure levels in children. Presence of abdominal fat has been demonstrated as a strong risk factor for obesity and cardiovascular risk. ${ }^{7}$ Low level of physical activity has also been detected as a risk factor for the development of cardiovascular diseases. ${ }^{8}$ Several Brazilian studies have demonstrated the presence of high blood pressure levels in children and adolescents. ${ }^{9-11}$ The objective of the present study is to establish the prevalence of hypertension and associated factors in children aged 7 to 12 years from the city of Caxias do Sul, state of Rio Grande do Sul, Brazil.

\section{Methods}

From April to August 2007, we conducted a crosssectional study involving elementary school students aged 7 to 12 years. The subjects were boys and girls enrolled at public (state and city) and private schools located in the urban area of the city of Caxias do Sul, state of Rio Grande do Sul, Brazil.

The present study is part of a larger study concomitantly performed and approved by the Research Ethics Committee of Universidade Luterana do Brasil with the purpose of establishing the blood pressure levels, as well as childhood obesity rate and lipid profile among schoolchildren from Caxias do Sul.

In order to estimate the sample size, we took into consideration students belonging to the age group being studied who were regularly enrolled in 2005 (33,241 students). For calculating the sample size, we considered hypertension prevalence of $20 \%$ (since there are studies that have shown different prevalences $\left.{ }^{12-14}\right), 95 \%$ confidence interval $(95 \% \mathrm{CI}), 80 \%$ power, acceptable error of three percentage points and design effect 2 to compensate possible losses and refusals and control for confounding factors. Examination of 1,400 children was necessary.

By applying the criterion of probability sampling, each school was considered a cluster, being included in the study according to their proportion of students. The proportion of students was maintained for their participation in the raffle, as well as the number of students from each type of school (state's or city's public or private school). A simple random sampling carried out using the Statistical Package for the Social Sciences (SPSS) 10.0 was used to select the students until the number of $\geq 1,400$ (necessary for this study) students was reached. Children who did not return the written consent form (which was handed out to the children 1 week before collection), who refused to participate even if they had the authorization and who were absent from school on the day of data collection after two attempts were considered losses. The loss percentage of this study was $3.2 \%$.
The pilot study was conducted in December 2006 with the purpose of standardizing data collection, as well as establishing the logistics of data collection and training and selection of the team of examiners, which was comprised of 36 volunteers (all of them were students of health related fields). Three examiners were selected to measure blood pressure levels.

The variables collected were: sex, skin color, socioeconomic indicator, level of physical activity, weight, height, waist circumference, systolic and diastolic blood pressure and 9-minute walking/running test, which were collected during one or two visits. Socioeconomic status was established according to the Brazilian National Economic Index ${ }^{15}$ (Índice Econômico Nacional, IEN), and the 9-minute walking and running test assessed the cardiorespiratory capacity, which was classified as below, above and within the zone of cardiorespiratory capacity. ${ }^{16}$

Blood pressure measurements were taken during one visit to the schools. The three measurements were taken every 2 minutes and were preceded by a 10-minute rest in the sitting position in a room where the three examiners were positioned apart from each other. The instruments used to measure blood pressure were Becton Dickinson ${ }^{\circledR}$ pediatric stethoscopes and cuffs and Cardiomed ${ }^{\circledR}$ and Oxigen ${ }^{\circledR}$ sphygmomanometers. All devices were tested by the National Institute of Metrology. The guidelines of the 4th Report of the National High Blood Pressure Education Program ${ }^{17}$ for blood pressure measurement were followed. Its categorization regarding sex, age and height percentile were also taken into consideration, classifying as normal the systolic and diastolic blood pressure levels lower than the values corresponding to the 90th percentile. Children with systolic and/or diastolic blood pressure levels $\geq 90$ th percentile and < 95th percentile were considered as pre-hypertensive and those with $>95$ th percentile were assumed to be hypertensive. In order to calculate the prevalence of high blood pressure levels, we used the third blood pressure measurement. A bivariate analysis of the independent variables was carried out using the chi-square test for a significant level of $5 \%$. The variables that showed statistically significant association were analyzed using logistic regression to control for possible confounding factors and to identify possible mediation effects of these variables.

\section{Results}

Our sample included 1,413 children; $50.5 \%(n=714)$ of them were boys, $80.7 \%$ were white, and $68.4 \%$ attended school during the afternoon. Four hundred and forty-five students (31.5\%) attended state's public schools, 770 (54.5\%) went to city's public schools and 198 (14\%) attended private schools. Age distribution is shown in Table 1. Mean age was 9.59 years (standard deviation $=1.54$ ). 
The percentage of overweight or obese children was 20 $(n=283)$ and $8.1 \%(n=114)$, respectively. And $31 \%$ of students from state's public schools were heavier than the normal weight for their height and age.

The mean systolic and diastolic blood pressure measurements 1,2 and 3 had a decreasing characteristic, since the mean systolic and diastolic blood pressure measurement 3 showed a lower value. There was a reduction of $1.52 \mathrm{mmHg}(1.48 \%)$ between the first and the third systolic measurement, and $0.76 \mathrm{mmHG}(1.16 \%)$ in the diastolic measurement.

For the classification of blood pressure levels, the values of the third measurement ${ }^{15}$ and the criteria of the National High Blood Pressure Education Program were used. ${ }^{17}$ Prevalence of hypertensive children was $8.4 \%$, and prehypertensive children accounted for $5.4 \%$ of the sample.

We found a significant difference $(p<0.001)$ between high blood pressure levels (pre-hypertensive and hypertensive children) and type of school (state's public, city's public and private schools).

In a bivariate analysis, the variable sex did not show a significant difference for high blood pressure levels. With regard to skin color, white children had 2.4 times greater chance of having high blood pressure levels $(p=0.001)$ (Table 1).

Table 1 - Distribution of students according to sociodemographic and economic characteristics, age group, type of school, and class time (Caxias do Sul, Brazil, 2007) $(\mathrm{n}=1,413)$

\begin{tabular}{|c|c|c|}
\hline Characteristic & $\mathbf{n}$ & $\%$ \\
\hline \multicolumn{3}{|l|}{ Age (years) } \\
\hline 7 & 144 & 10.2 \\
\hline 8 & 255 & 18.0 \\
\hline 9 & 270 & 19.1 \\
\hline 10 & 288 & 20.4 \\
\hline 11 & 274 & 19.4 \\
\hline 12 & 182 & 12.9 \\
\hline \multicolumn{3}{|l|}{ Sex } \\
\hline Female & 699 & 49.5 \\
\hline Male & 714 & 50.5 \\
\hline \multicolumn{3}{|l|}{ Skin color } \\
\hline White & 1,128 & 80.7 \\
\hline Non-white & 269 & 19.3 \\
\hline \multicolumn{3}{|l|}{ Type of school } \\
\hline State's public schools & 445 & 31.5 \\
\hline City's public schools & 770 & 54.5 \\
\hline Private schools & 198 & 14.0 \\
\hline \multicolumn{3}{|l|}{ Class time } \\
\hline Morning & 447 & 31.6 \\
\hline Afternoon & 966 & 68.4 \\
\hline \multicolumn{3}{|l|}{ IEN } \\
\hline Low & 124 & 10.7 \\
\hline Middle & 351 & 30.4 \\
\hline High & 679 & 58.8 \\
\hline
\end{tabular}

IEN = Brazilian National Economic Index (Índice Econômico Nacional).
Taking into consideration the socioeconomic status classified by the IEN, ${ }^{12}$ students who belonged to a high social class also had a greater chance of having high blood pressure levels [prevalence ratio $(P R)=2.6$; IC95\% 2.2523.095] according to a bivariate analysis. In the multivariate analysis, the increased chance remained after adjusting for the other variables (Table 2 ).

Children with increased waist circumference had greater chance of having high blood pressure ( $P R=2.5$ and $95 \%$ IC 2.176-2.928). On the other hand, better aerobic capacity on the 9-minute running test (children considered within and above the healthy zone) was a protective factor against high blood pressure levels ( $P R=0.794$ and 0.779 ) in the bivariate and multivariate analyses, respectively (Table 2 ).

When comparing among the different types of schools, there was significant difference, since private schools had almost twice more children $(24.7 \%)$ with high blood pressure than state's public (13.5\%) and city's public schools (11.3\%) (Table 3).

The percentage of children with high blood pressure was statistically higher $(p=0.001)$ in obese or overweight children, according to Figure 1.

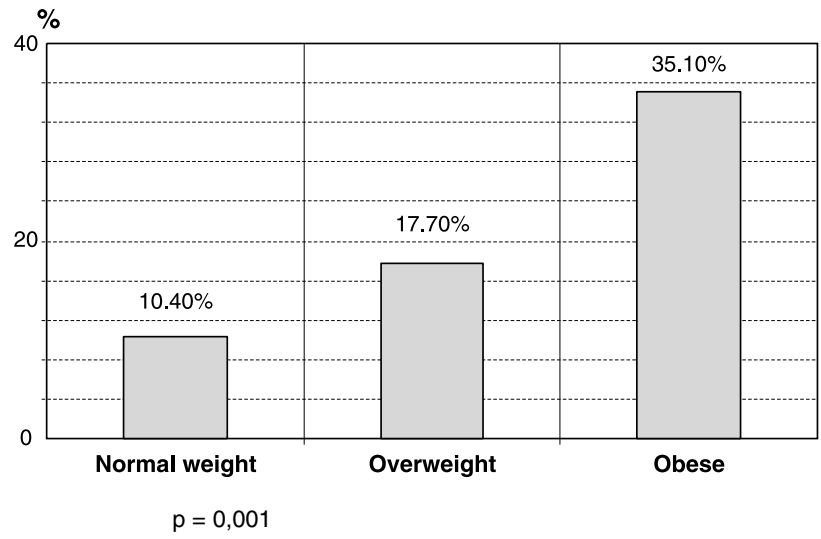

Figure 1 - Percentage distribution of children with high blood pressure levels considering the nutritional status of students from Caxias do Sul, Brazil $(n=1,413)$

\section{Discussion}

Epidemiological studies have demonstrated the importance of measuring blood pressure during childhood and adolescence, ${ }^{7,18}$ since the increase in the blood pressure levels of youths translates into a greater chance of having high blood pressure in adulthood, producing an increased risk of cardiovascular diseases. ${ }^{19}$

In the present study, we performed three blood pressure measurements during one visit to the schools. These measurements had a decreasing behavior, which is in agreement with some authors according to whom the number 
Table 2 - Crude and adjusted prevalence ratio for HBP (Caxias do Sul, Brazil, 2007) $(n=1,413) *$

\begin{tabular}{|c|c|c|c|c|c|c|c|c|}
\hline \multirow[b]{2}{*}{ Variables } & \multirow[b]{2}{*}{ n (\%) } & \multirow[b]{2}{*}{ HBP (\%) } & \multicolumn{3}{|c|}{ Bivariate analysis } & \multicolumn{3}{|c|}{ Multivariate analysis } \\
\hline & & & Crude PR & $95 \% \mathrm{CI}$ & $\mathbf{p}$ & Adjusted PR & $95 \% \mathrm{CI}$ & $\mathbf{p}$ \\
\hline Skin color & & & & & 0,001 & & & 0,001 \\
\hline Non-white & $269(19.3)$ & 1.2 & 1.00 & & & 1.00 & & \\
\hline White & $1,128(80.7)$ & 7.6 & 2.42 & $2.16-2.72$ & & 1.72 & $1.46-2.02$ & \\
\hline IEN & & & & & 0.001 & & & 0.001 \\
\hline Low & $124(10.7)$ & 0.2 & 1.00 & & & 1.00 & & \\
\hline Middle & $351(30.4)$ & 2.7 & 1.39 & $1.15-1.69$ & & 1.11 & $0.89-1.39$ & 0.33 \\
\hline High & $679(58.8)$ & 5.6 & 2.64 & $2.25-3.09$ & & 1.69 & $1.38-2.6$ & 0.001 \\
\hline Waist circumference & & & & & 0.001 & & & 0.00 \\
\hline Appropriate & $1,078(76.3)$ & 4.7 & 1.00 & & & 1.00 & & \\
\hline Increased & $335(23.7)$ & 4.0 & 2.82 & $2.51-3.18$ & & 2.52 & $2.17-2.92$ & \\
\hline Aerobic capacity & & & & & 0.001 & & & 0.001 \\
\hline Below the healthy zone & $810(59.0)$ & 5.2 & 1.00 & & & 1.00 & & \\
\hline Within the healthy zone & $564(41.0)$ & 3.6 & 0.79 & $0.71-0.88$ & & 0.77 & $0.67-0.90$ & \\
\hline
\end{tabular}

$95 \% \mathrm{Cl}=95 \%$ confidence interval; HBP = high blood pressure; IEN = Brazilian National Economic Index (Índice Econômico Nacional); PR = prevalence ratio. ${ }^{*}$ Adjusted for skin color, IEN, waist circumference and aerobic capacity.

of measurements provides a decrease in the prevalence of high blood pressure, since anxiety during measurements can have an influence on the measured value. ${ }^{10,20-22}$ Therefore, we used the third blood pressure measurement, since Borges et al. ${ }^{10}$ suggested that such measurement is the one that best represents baseline blood pressure levels measured in students during only one visit.

In the bivariate analysis, white children had 2.4 times greater chance of having high blood pressure levels than non-white children. Such finding may be explained by the fact that there is a higher percentage of obese/overweight individuals among white children. In the multivariate analysis, however, the variable skin color showed determining power with significant level until the last phase of the analysis in the theoretical model defined for this study. Such results are in agreement with findings from other studies $^{14,21,22}$ that demonstrated a higher prevalence of white children with high blood pressure.
Individuals belonging to middle and high social classes according to the IEN had 1.39 and 2.6 times greater chance of having high blood pressure levels, respectively, than those belonging to a low social class. Garcia et al. ${ }^{11}$ showed a strong association between individuals who had high urban quality of life and high blood pressure levels. It seems that the socioeconomic status provides large amounts of food and different life style and environment, what may contribute to this type of association.

Hypertension and obesity have been directly related in several studies. ${ }^{19,21,22}$ Increased waist circumference in children has been demonstrated to be a risk factor, since abdominal fat may cause heart diseases. ${ }^{23}$ Our results demonstrated that children with increased waist circumference have 2.8 times greater chance of having high blood pressure levels than children with appropriate waist circumference. This result remained the same in the multivariate analysis ( $P R=2.5$ and 95\%IC 2.176-2.928).

Table 3 - Distribution of blood pressure levels among state's public, city's public and private schools (Caxias do Sul, Brazil, 2007)

\begin{tabular}{lccc}
\hline & \multicolumn{3}{c}{ Blood pressure levels } \\
\cline { 2 - 4 } Type of school & High, n (\%) & Normal, n (\%) & Total, n (\%) \\
\hline State's public schools & $60(13.5)$ & $385(86.5)$ & $445(100)$ \\
City's public schools & $87(11.3)$ & $683(88.7)$ & $770(100)$ \\
Private schools & $49(24.7)$ & $149(75.3)$ & $198(100)$ \\
Total & $196(13.9)$ & $1,217(86.1)$ & $1,413(100)$ \\
\hline
\end{tabular}


The measurement of waist/abdominal circumference 24,25 and/or other indicators of the nutritional status in children have been presented as an important aspect to be assessed during pediatric medical visits, ${ }^{26}$ since children have been showing increasing weight gain.

In terms of physical capacity, children who were classified within the healthy zone on the 9-minute walking/running test had a protective factor against high blood pressure levels. However, such relation may be established, since those children with higher blood pressure levels were also obese and overweight (body mass index or waist circumference). ${ }^{27}$ Therefore, it is possible to assume that the nutritional status is a determining factor for the inadequate performance on a running test. 28 Other studies have not shown an association between high blood pressure and poor performance on aerobic capacity tests. ${ }^{8}$ We believe that such divergent data resulted from the different age groups, methodologies and protocols used, as well as several factors that have an influence on blood pressure, mainly during childhood. It might be suggested that having adequate weight may reduce the association with high blood pressure and low aerobic capacity.

The prevalence rates of high blood pressure levels among students found in the present study are in agreement with the findings of a study by Paradis et al., ${ }^{13}$ in which the population examined had a prevalence rate of 12 and $14 \%$ of high blood pressure for boys and girls, respectively. Studies conducted in other regions of Brazil demonstrated different prevalence rates. Moura et al. ${ }^{9}$ found $6.5 \%$ and Oliveira et al. ${ }^{14}$ found $3.6 \%$. Such differences may be caused by the ethnic and economic characteristics of the populations studied, as well as the parameters employed to measure blood pressure levels.

Blood pressure measurement performed during only one visit, due to operational problems, is a limitation of our study, since it may overestimate children's blood pressure. In addition, we did not use kappa test for the standardization of blood pressure examiners; however, an intense training program including much information was provided. Another limitation of our study was the indirect measurement of abdominal fat using waist circumference measurement, since it makes it impossible to determine if such measurement indicates the presence of visceral or subcutaneous abdominal fat.

Taking into consideration the epidemiologic characteristic of the present study, whose objective was the screening and referral of these individuals to a health service, we would like to draw the attention of the community and governments to the care of cardiovascular health among children.

Therefore, we conclude that the prevalence of high blood pressure levels among children aged 7 to 12 years was $13.9 \%$, and there was no statistically significant difference in the prevalence of these high blood pressure levels between sexes. White children belonging to a high social class were significantly more likely to have high blood pressure, and having increased waist circumference provides statistically higher chances of having high blood pressure levels.

The extent of our study enables us to suggest that this type of population groups may be followed-up throughout life, resulting in the implementation of epidemiological databases with the purpose of revealing the actual triggering factors of chronic pathologies, thus making it possible to take epidemiologically useful measures, trying to prevent diseases and promote health education. Our results should be cautiously considered, since cross-sectional studies are susceptible to reverse causality, and the use of odds ratio to measure association may overestimate the effect magnitude of our findings.

\section{References}

1. World Health Organization (WHO). Global strategy on diet, physical activity and heath. Cardiovascular disease prevention and control. http://www.who.int/dietphysicalactivity/publication/ facts/cvd/en/ Access: 12/04/2006.

2. Brasil. Ministério da Saúde. A vigilância, o controle e a prevenção das doenças crônicas não-transmissíveis: DCNT no contexto do Sistema Único de Saúde brasileiro. Brasília, DF: OMS; 2005

3. Schramm JM, Oliveira AF, Leite IC, Valente JG, Gadelha AM, Portela MC, et al. Transição epidemiológica e o estudo de carga de doença no Brasil. Cienc Saude Coletiva. 2004;9:897-908.

4. Sorof J, Daniels S. Obesity hypertension in children: a problem of epidemic proportions. Hypertension. 2002;40:441-7.

5. Bao W, Theefoot SA, Srinivasan SR, Berenson GS, Essential hipertensión predicted by tracking of elevated blood pressure from childhood to adulthood: the Bogalusa Herat Study. Am J Hyperens. 1995; 8:657-65.

6. Daniels SR. Cardiovascular sequelae of childhood hypertension. Am J Hypertens. 2002; 15:61S-63S.

7. Hall JE, Crook ED, Jones DW, Wofford MR, Dubbert PM. Mechanisms of obesity-associated cardiovascular and renal disease. Am J Med Sci. 2002;324:127-37.

8. Rodrigues AN, Perez AJ, Carletti L, Bissoli NS, Abreu GR. The association between cardiorespiratory fitness and cardiovascular risks in adolescents. J Pediatr (Rio J). 2007;83:429-35.

9. Moura AA, Silva MA, Ferraz MR, Rivera IR. Prevalência de pressão arterial elevada em escolares e adolescentes de Maceió. J Pediatr (Rio J). 2004;80:35-40.

10. Borges LM, Peres MA, Horta BL. Prevalência de níveis pressóricos elevados em escolares de Cuiabá, Mato Grosso. Rev Saude Publica. 2007; 41:530-8.

11. Garcia FD, Terra AF, Queiroz AM, Correia CA, Ramos PS, Ferreira QT, et al. Avaliação de fatores de risco associados com elevação da pressão arterial em crianças. J Pediatr (Rio J). 2004;80:29-34.

12. Munger RG, Prineas RJ, Gomez-Marin O. Persistent elevation of blood pressure among children with a family history of hypertension: the Minneapolis Children's Blood Pressure Study. J Hipertens. 1988;6:647-53.

13. Paradis G, Lambert M, O'Loughlin J, Lavallée C, Aubin J, Delvin E, et al. Blood pressure and adiposity in children and adolescents. Circulation. 2004;110:1832-8. 
14. Oliveira AM, Oliveira AC, Almeida MS, Almeida FS, Ferreira JB, Silva $C E$, et al. Fatores ambientais e antropométricos associados à hipertensão arterial infantil. Arq Bras Endocrinol Metabol. 2004;48:849-54.

15. Barros AJ, Victora CG. Indicador econômico para o Brasil baseado no censo demográfico de 2000. Rev Saude Publica 2005;39:523-9.

16. Setor de Pedagogia do Esporte do CENESP-UFRGS. PROESPBR, Projeto Esporte Brasil - Indicadores de Saúde e Fatores de Prestação Esportiva em Crianças e Jovens. Manual de Aplicação de Medidas e Testes Somatomotores. Perfil. 2002;4: 9-34.

17. National High Blood Pressure Education Program Working Group on High Blood Pressure in Children and Adolescent: the fourth report on the diagnosis, evaluation, and treatment of high blood pressure in children and adolescents. Pediatrics. 2004;114:555-76.

18. National High Blood Pressure Education Program Working Group on Hipertension Control in Children and Adolecents. Update on the 1987 Task Force Report on High Blood Pressure in Children and Adolescents: a working group report from the National High Blood Pressure Education Program. Pediatrics. 1996;98:649-58.

19. Li X, Li S, Ulusoy E, Chen W, Srinivasan SR, Berenson GS. Childhood adiposity as a predictor of cardiac mass in adulthood: The Bogalusa Heart Study. Circulation. 2004;110:3488-92.

20. Salgado CM, Carvalhaes JT. Hipertensão arterial na infância. J Pediatr (Rio J). 2003;79:S115-24.

21. Gillman MW, Cook NR. Blood pressure measurement in childhood epidemiological studies. Circulation. 1995;92:1049-57.

22. Rosner B, Prineas R, Daniels SR, Loggie J. Blood pressure differences between blacks and whites in relation to body size among US children and adolescents. Am J Epidemiol. 2000;151:1007-19.
23. Janssen I, Katzmarzyk PT, Srinivasan SR, Chen W, Malina RM, Bouchard C, et al. Combined influence of body mass index and waist circumference on coronary artery disease risk factors among children and adolescents. Pediatrics. 2005;115:1623-30

24. McCarthy HD, Jarret KV, Emmett PM, Rogers I.Trends in waist circumferences in young British children: a comparative study. Int J Obes. 2005;29:157-62.

25. Ribeiro RQ, Lotufo PA, Lamounier JA, Oliveira RG, Soares JF, Botter DA. Fatores adicionais de risco cardiovascular associados ao excesso de peso em crianças e adolescentes: o estudo do coração de Belo Horizonte. Arq Bras Cardiol. 2006;86:408-18.

26. Almeida CA, Pinho AP, Ricco RG, Elias CP. Abdominal circumference as an indicator of clinical and laboratory parameters associated with obesity in children and adolescents: comparison between two reference tables. J Pediatr (Rio J). 2007;83:181-5.

27. He Q, Ding ZY, Fong DY, Karlberg J. Blood pressure is associated with body mass index in both normal and obese children. Hypertension. 2000;36:165-70.

28. Giugliano R, Carneiro EC. Fatores associados à obesidade em escolares. J Pediatr (Rio J). 2004;80:17-22.

\author{
Correspondence: \\ Cristine Boone Costanzi \\ Rua Luiz Casara, 541/402 \\ CEP 95098-520 - Caxias do Sul, RS - Brazi \\ Tel.: +55 (54) 9945.4475 \\ E-mail: cristine.costanzi@gmail.com
}

